\title{
A New Septum in the Female Breast
}

\author{
Mostafa Abdel Rahman Awad ${ }^{1}$, Mahmoud Magdi Sherif ${ }^{1}$, Eaman Yahya Sadek ${ }^{1}$, \\ Hesham Aly Helal ${ }^{1}$, Wafaa Raafat Abdel Hamid ${ }^{2}$ \\ Departments of ${ }^{1}$ Plastic and Reconstructive Surgery and ${ }^{2}$ Radiodiagnosis, Ain Shams University, Cairo, Egypt
}

Background Understanding the female breast fascial system is of paramount importance in breast surgery. Little was written about breast ligaments. Most articles refer to Cooper's work without further anatomical studies. Lately, a horizontal septum has been described conveying nerves and vessels to the nipple areola complex.

Methods During the surgical dissection of the lower part of the breast, in supero-medial technique for breast reduction operations, a fascial septum between the lower two quadrants was detected. This fibrous septum was studied through anatomic dissection of breast tissues during routine breast reshaping procedures that was done on 30 female patients. Magnetic resonance imaging (MRI) was performed preoperatively in all cases and correlated with the intraoperative findings. In the other five cases, outside the clinical study, the imaging was done during routine investigation for breast swellings.

Results A vertical septum was identified in the lower part of the breast, lying at the breast meridian between the two lower quadrants. It is a tough bi-laminated structure that extends from the middle of the infra-mammary crease caudally to nipple-areola complex cranially and from the pectoral fascia posteriorly to the overlying skin anteriorly. This was proved by MRI findings.

Conclusions This study describes a new inferior vertical septum which separates the lower half of the breast into two definite anatomical compartments: medial and lateral.

Keywords Breast / Mammaplasty / Fascia / Ligaments
Correspondence: Hesham Aly Helal Department of Plastic and Reconstructive Surgery, Ain Shams University, 80A Thawra Street, Heliopolis, Cairo, Egypt Tel: $+20-24150250$ Fax: +20-24150250 E-mail: drheshamhelal75@yahoo.com

Special thanks to Mr. Mohammad ElHamahmy (Lecturer, Faculty of Arts) for drawing the illustrations which are the authors' own creation.

This study was presented in the 44th Annual Congress of the Egyptian Society of Plastic and Reconstructive Surgeons on 18-21 February 2014, in El Gouna, Egypt.

No potential conflict of interest relevant to this article was reported.

Received: 12 Dec $2015 \bullet$ Revised: 10 Nov $2016 \bullet$ Accepted: 10 Dec 2016

pISSN: 2234-6163 • elSSN: 2234-6171 • https://doi.org/10.5999/aps.2017.44.2.101・ Arch Plast Surg 2017:44:101-108

\section{INTRODUCTION}

Despite the importance of fascial ligaments and supporting septa in the female breast, little was written about them. Cooper [1] in 1840, described fibrous septa extending from the skin to the pectoral fascia dividing the breast into lobes and lobules. He considered these septa as the supporting system of the breast parenchyma.

Bayati and Seckel [2] identified a ligament originating from the fifth rib medially and the fascia between the fifth and sixth ribs laterally to insert into the deep dermis of the infra-mamma- ry crease (IMF). Presence of such ligament has its proponents $[3,4]$ as well as opponents [5-7]. Nava et al. [4] identified a pseudo-ligamentous lamina detaching off the superficial fascia along the entire infra-mammary fold and runs in subcutaneous tissue to reach the areola, essential in the formation of its contour. The adherence between superficial and deep fascia is made up of multiple short fibrous connections that don't cross the muscular wall [5].

Wuringer and Collegues $[8,9]$ described a horizontal septum delivering nerve and vessels to the nipple. At its borders the septum curves upward into vertical medial and lateral extensions 
attaching the breast to the sternum and lateral edge of pectoralis minor respectively. It acts with its extensions as a brassiere-like suspensory system.

Since many years, we have been using the medially-based pedicle; Findlay's technique [10], in breast reduction and during this procedure, a vertical tough midline fibrous structure was usually noticed in the lower central part of the breast. The aim of our recent study is to confirm its existence and investigate all the characteristics of this newly described septum. To this purpose, an anatomical study was performed on 30 female patients to demonstrate the location, structure, shape, length and thickness of this vertical septum. Additionally a radiological study using magnetic resonance imaging (MRI) was done to confirm and correlate with the anatomical findings.

\section{METHODS}

The study included:

\section{Anatomical study}

The fibrous septum was studied through anatomic dissection of breast tissues of 30 female patients ( 60 breasts) during breast reduction. All the data gathered for the study was from the right breast only while dissection of the left breast was only for verification of presence. Age ranged between 25 and 40 years old. Transposition of nipple and areola complex (NAC) was done using supero-medial pedicle in 10 cases, inferior pedicle in 5 cases and superior pedicle in 15 cases. Excised tissue ranged from $480 \mathrm{~g}$ to $2.2 \mathrm{~kg}$, from each breast. Patients with previous breast surgery or breast diseases were excluded. The septum was accessed clinically by dissecting the lower pole of the breast starting by incising the skin at medial and lateral margins of skin resection down to the pectoral fascia then meticulous blunt dissection proceeds towards the already marked breast meridian where a tough fibrous barrier stretching from mid-inframammary point up to the NAC is present and hinder crossing the meridian (Fig. 1). Specific fragment measuring $3 \times 3 \mathrm{~cm}$ of both the horizontal and the newly described septum was taken as surgical specimens and submitted to histological examination and collagen content quantification.

\section{MRI study}

Comprehensive MRI study of breast was performed including $\mathrm{T} 1$ weighted (T1W), T2W, fat suppressed (vessel sensitive sequence), diffusion weighted images (DWI) and axial images with or without post contrast enhancement as recommended $[11,12]$. All of the 30 cases that had reduction mammaplasty had preoperative MRI and imaging findings were correlated

\section{Fig. 1. Anatomical location of septum}

The septum (thick white arrow) at mid IMF (black arrow) dividing the lower part of breast into medial and lateral compartments. IMF, infra-mammary crease.

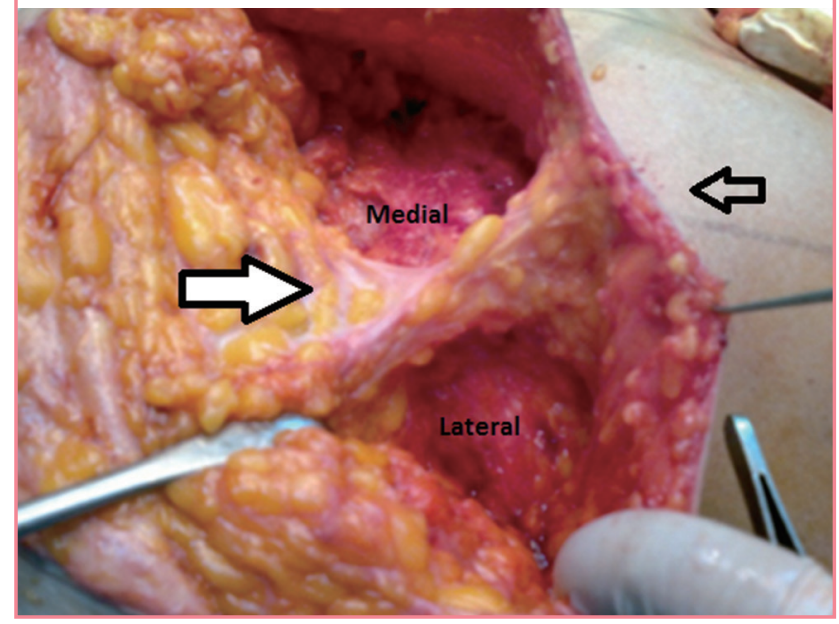

with intraoperative findings. Five more patients with suspected breast tumors had MRI as routine imaging to provide evidence of existence and give a more concrete concept of its structure.

\section{RESULTS}

\section{The anatomical study}

A well-formed, tough, bi-laminar vertical septum was found in the midline of the lower part of the breast in all of the cases. It divides the lower part of breast into medial and lateral compartments.

It extends from pectoral fascia posteriorly to overlying skin anteriorly with a length ranging from 6 to $12 \mathrm{~cm}$ (measured midway between the NAC and IMF using a ruler). It also extends from mid IMF caudally to NAC cranially with a length ranging from 10 to $17 \mathrm{~cm}$ (Fig. 2). It is a thick bi-laminar structure with its thickness ranged from 0.5 to $1.3 \mathrm{~cm}$ (measured by a sliding caliber) and could be split into two definite layers (Fig. 3).

An intercostal perforator could be detected piercing the pectoralis major muscle and apparently heading towards the NAC guided by the fibrous septum (Fig. 4). The amount of fat found within the septum was proportional to the general fat content of the breast. In very large breasts, surrounding fat globules penetrate the septum causing its thinning (Fig. 5).

The result of the histological examination showed that both septa were composed of collagenous tissue, predominantly of type I collagen with quantitative assessment showing more content of collagen type I in our vertical septum than the horizontal one in 25 breasts $(83.3 \%)$.

All patients' data and results of the anatomical study are sum- 


\section{Fig. 2. Extension of septum}

The septum extending from mid IMF (black arrow) caudally to the level of the NAC cranially. IMF, infra-mammary crease; NAC, nipple areola complex.

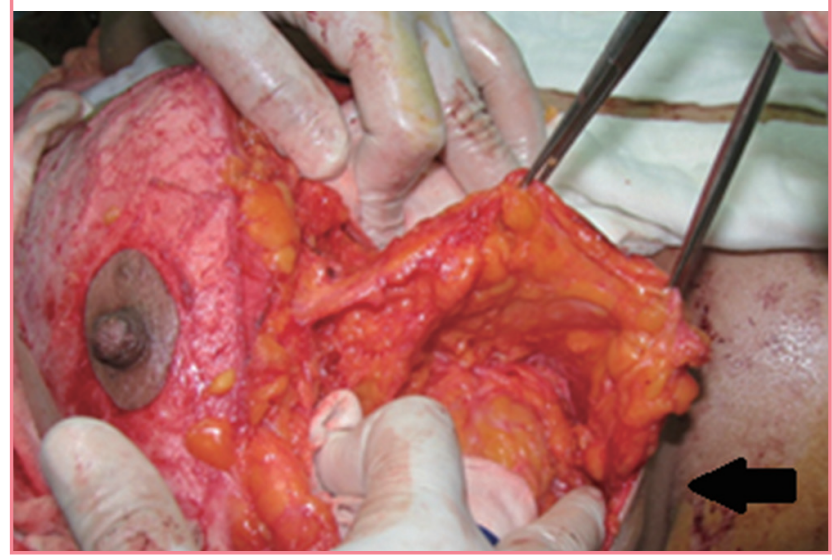

\section{Fig. 3. Split of septum}

Split of vertical septum.

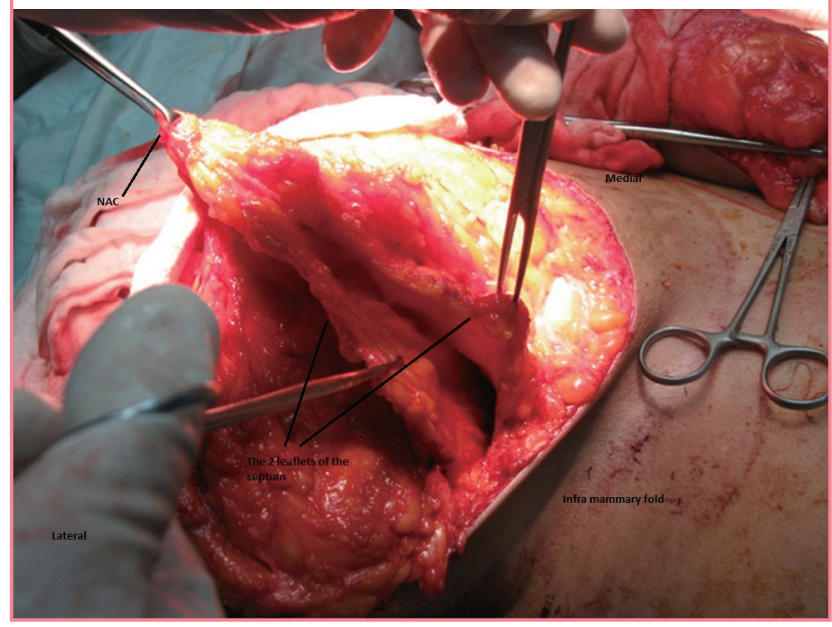

marized in Table 1.

\section{The MRI study}

The breast is made up of glandular content normally acquiring dark signals on T1W images and T2W images and being of mixed signal intensity on fat suppressed images. The fatty background is diffusely bright on T1W and T2W images and turns dark on fat suppressed images. Cooper's ligaments and connective tissue contents appear dark on all sequences.

The vertical septum was better demonstrated in axial images. It appeared as a linear dark structure extending from pectoral fascia posteriorly into breast parenchyma anteriorly. It was usually central in location, beginning inferiorly from the mid-inframammary point upwards toward NAC. It represented an invagination of the pectoral fascia into breast parenchyma, dividing
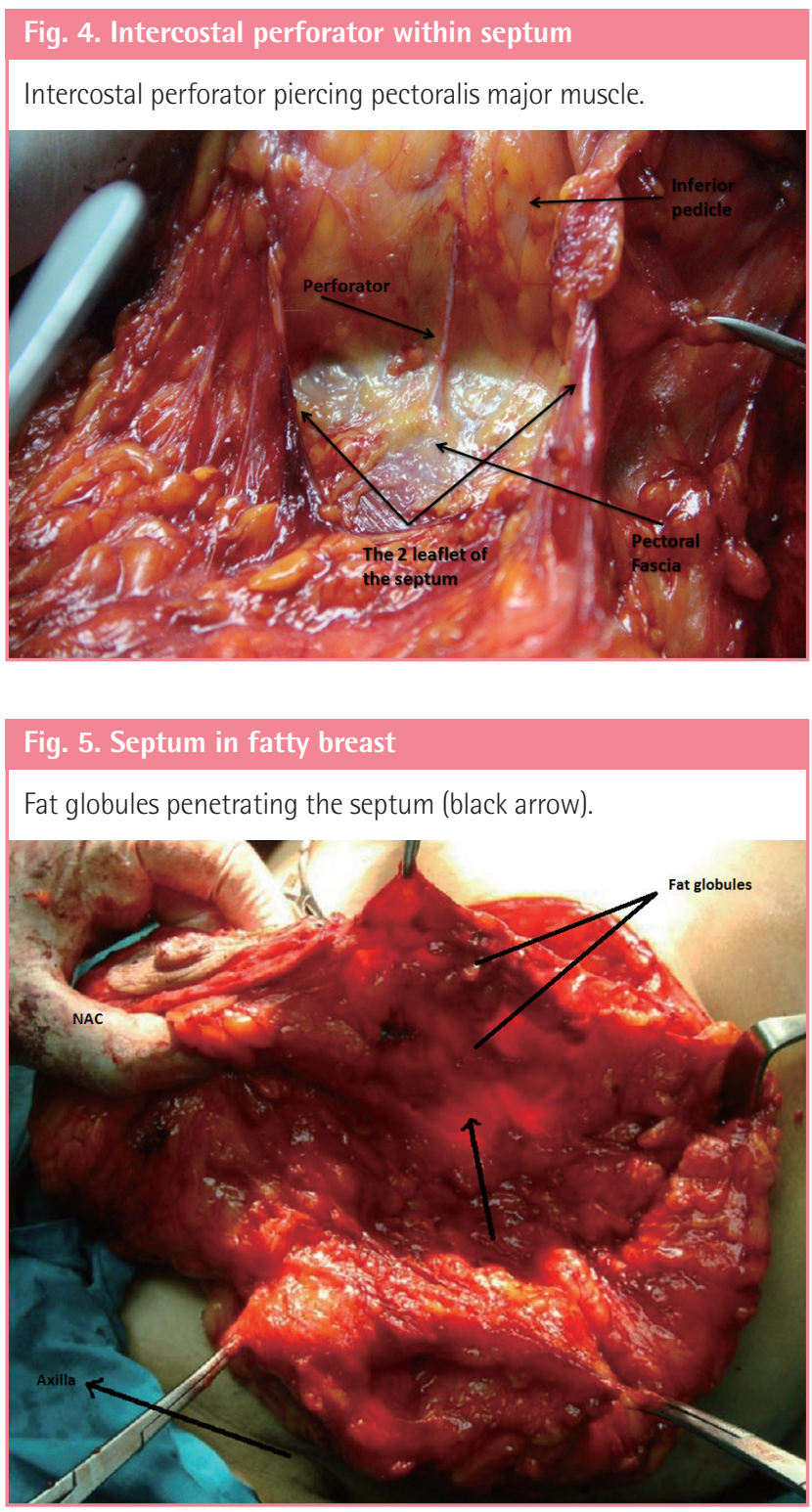

the inferior aspect of breast into medial and lateral quadrants. In 3 breasts of them, there was minimal lateral paramedian deviation by: $5.3,6.8$, and $10.4 \mathrm{mms}$.

The length of the septum ranged from 6.2 to $10.4 \mathrm{~cm}$. Its thickness was between 4.3 and $12.8 \mathrm{~mm}$. Moderately sized breasts showed a septum with uniform thickness all through its length, others have a septum which is thickened posteriorly, thinned out anteriorly with a difference in thickness and in fat content (Fig. 6). Large fatty breasts had equally fatty and fibroglandular tissues (ACR 2) except for three cases that were predominantly fatty on expense of fibro-glandular components (ACR 1). The septum was either: attenuated, appearing as an interrupted linear structure or completely non-visualized. It showed an uneven thickness with signal interruption ranging between zones of non-visualization and the $3.8 \mathrm{~mm}$ thick-wall 
Table 1. Patients' data and septum characteristics

\begin{tabular}{|c|c|c|c|c|c|c|c|}
\hline No. & Age (yr) & Marital status & Lactation & Breast volume & $\begin{array}{c}\text { Dimensions of the } \\
\text { septum (W-L-T) }\end{array}$ & $\begin{array}{l}\text { Type I collagen in } \\
\text { vertical septum }\end{array}$ & $\begin{array}{l}\text { Type I collagen in } \\
\text { transverse septum }\end{array}$ \\
\hline 1 & 28 & Married & Yes & 429.9 & $10 \times 6 \times 1.3$ & 244.367 & 213.687 \\
\hline 2 & 28 & Married & Yes & 770 & $13 \times 7 \times 0.9$ & 234. 240 & 227.954 \\
\hline 3 & 38 & Married & Yes & 857 & $14 \times 8 \times 1$ & 230.841 & 227.714 \\
\hline 4 & 45 & Married & Yes & 1,370 & $17 \times 12 \times 0.5$ & 250.099 & 251.270 \\
\hline 5 & 26 & Married & Yes & 539 & $12 \times 8 \times 1.2$ & 260.696 & 253.580 \\
\hline 6 & 23 & Single & No & 980 & $13 \times 7.5 \times 0.8$ & 234.692 & 242.787 \\
\hline 7 & 34 & Married & Yes & 488 & $10 \times 6.5 \times 1.2$ & 247.146 & 251.638 \\
\hline 8 & 28 & Married & Yes & 1,030 & $15 \times 6.5 \times 0.5$ & 260.692 & 250.104 \\
\hline 9 & 29 & Married & Yes & 880 & $13 \times 8 \times 0.7$ & 243. 899 & 239. 593 \\
\hline 10 & 37 & Married & Yes & 807 & $13 \times 7 \times 0.8$ & 239. 029 & 243. 662 \\
\hline 11 & 49 & Married & Yes & 530 & $10 \times 7 \times 0.9$ & 261.295 & 229. 340 \\
\hline 12 & 30 & Married & Yes & 940 & $14 \times 10 \times 0.5$ & 258.872 & 241.246 \\
\hline 13 & 26 & Single & No & 777 & $11 \times 7 \times 0.7$ & 265.758 & 241.975 \\
\hline 14 & 37 & Married & Yes & 704 & $12.5 \times 8 \times 0.6$ & 265. 849 & 245.708 \\
\hline 15 & 32 & Married & Yes & 993 & $13 \times 11 \times 0.7$ & 253.593 & 236.500 \\
\hline 16 & 39 & Married & Yes & 1,024 & $15 \times 12 \times 0.5$ & 255.649 & 245.139 \\
\hline 17 & 41 & Married & Yes & 931 & $14 \times 11 \times 0.6$ & 256.665 & 239. 407 \\
\hline 18 & 44 & Married & Yes & 972 & $13 \times 9 \times 0.6$ & 265.553 & 239. 871 \\
\hline 19 & 25 & Married & Yes & 699 & $12 \times 6 \times 0.8$ & 253.758 & 231.128 \\
\hline 20 & 24 & Single & Yes & 816 & $12 \times 7 \times 0.7$ & 245.557 & 224.530 \\
\hline 21 & 32 & Married & Yes & 900 & $14 \times 9 \times 0.5$ & 224. 696 & 225.133 \\
\hline 22 & 38 & Married & Yes & 813 & $13 \times 8 \times 0.7$ & 261.656 & 230.848 \\
\hline 23 & 45 & Married & Yes & 533 & $12 \times 6.5 \times 1.1$ & 239. 040 & 234. 297 \\
\hline 24 & 30 & Married & Yes & 779 & $11.5 \times 7 \times 0.8$ & 258.443 & 229. 299 \\
\hline 25 & 40 & Married & Yes & 421 & $10 \times 6 \times 1.2$ & 277.883 & 214.568 \\
\hline 26 & 38 & Single & No & 880 & $11 \times 7 \times 0.9$ & 256. 296 & 224.524 \\
\hline 27 & 44 & Married & Yes & 616 & $11 \times 7 \times 0.9$ & 261.341 & 220.962 \\
\hline 28 & 25 & Married & Yes & 857 & $13 \times 8 \times 0.7$ & 248. 887 & 238.667 \\
\hline 29 & 24 & Married & Yes & 500 & $12 \times 7 \times 1$ & 252. 346 & 212. 889 \\
\hline 30 & 37 & Married & Yes & 530 & $10.5 \times 7 \times 1.1$ & 247.653 & 228. 889 \\
\hline
\end{tabular}

\section{Fig. 6. Radiological view of septum}

Right side: the two laminae (red arrows) split anteriorly, accommodating fat within its potential space. Left side: septum (green arrow) is thicker posteriorly, thinned out anteriorly with no definite contents. T2W, T2 weighted.

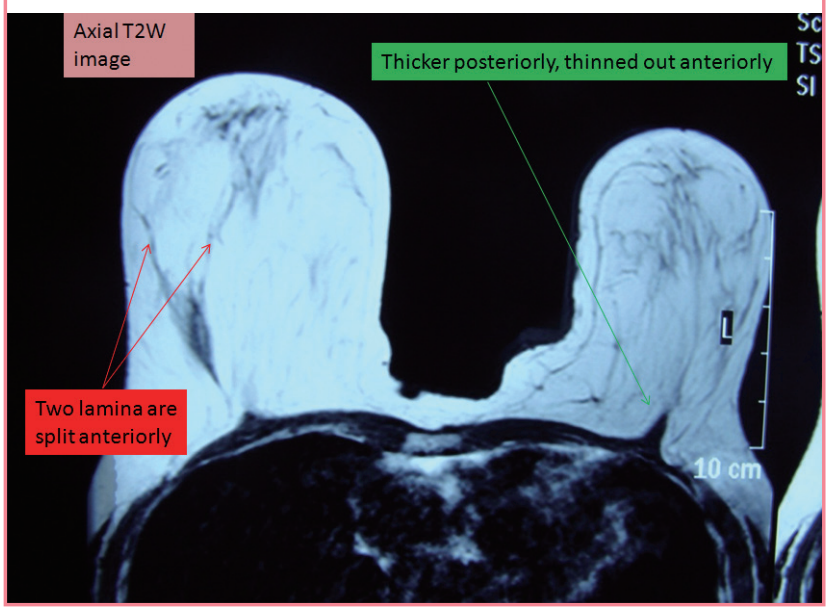

\section{Fig. 7. Radiological view of perforator}

Right inferior septal predominance accommodating a vessel of caliber $3.1 \mathrm{~mm}$ (red arrows) in comparison to the left.

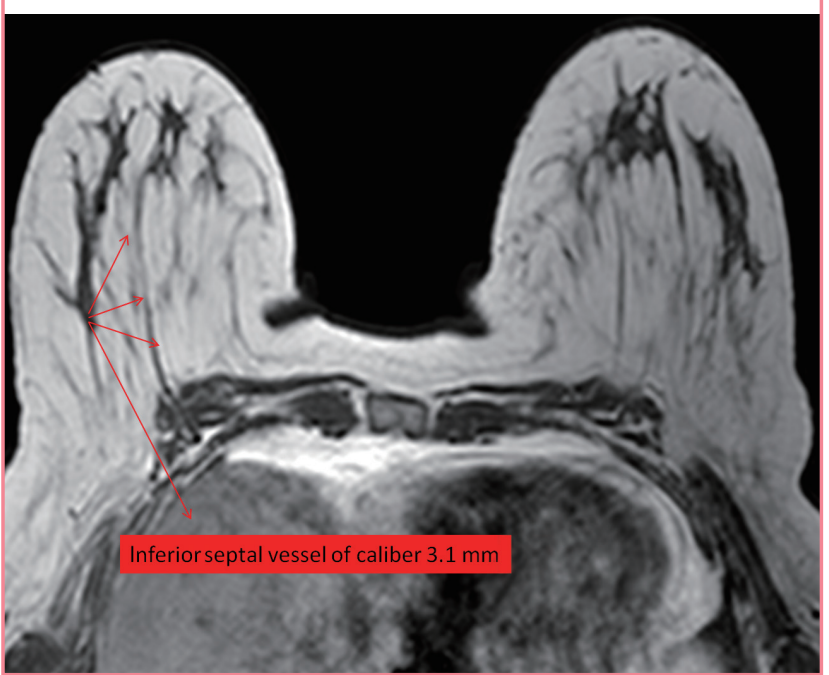




\section{Fig. 8. Radiological view of septum in fatty breast}

Very thin right breast septum accommodating a vessel only visualized within its posterior half (red arrow). The anterior half of septum appears remarkably attenuated with interrupted signal likely attributed to invaginations by fat lobules. The left breast septum could not be visualized on any of the magnetic resonance sequences. T2W, T2 weighted.

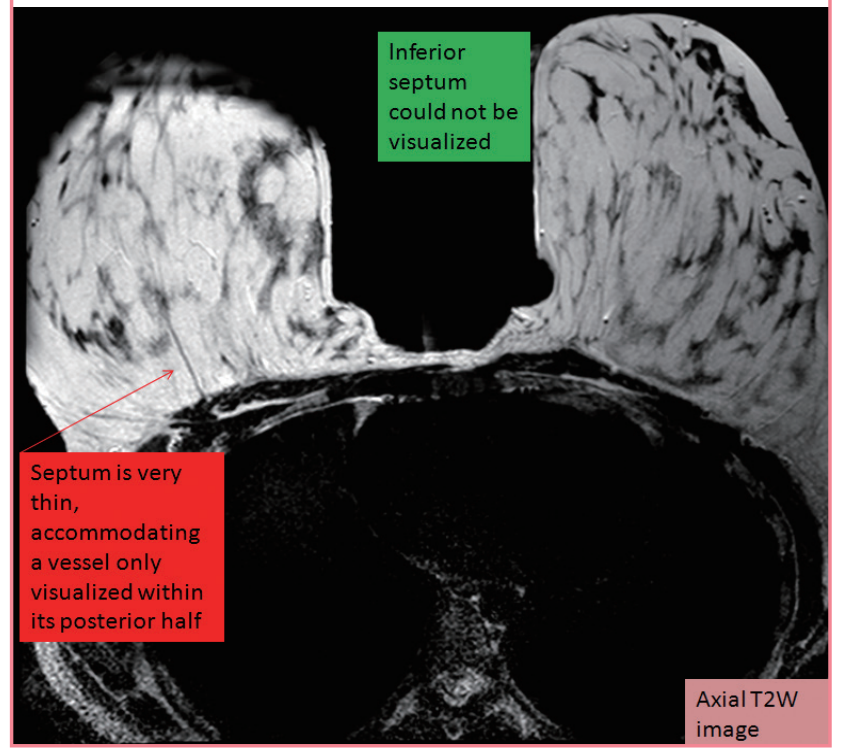

\section{Fig. 9. Septum in mastectomy case}

A case had a left side mastectomy, with the septum on the right side is seen as a uniform structure containing a vessel within its confines (red arrows).

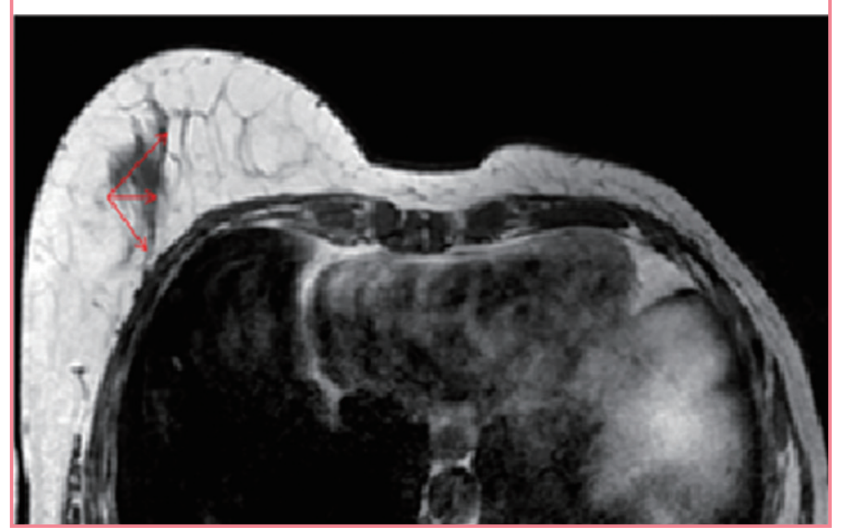

of the septum.

A vessel was detected in the potential space of the septum in 28 cases; the caliber varied between 3.1 and $3.8 \mathrm{~mm}$ (Figs. 7, 8). For the other five patients who had a routine imaging for suspected breast tumor; two cases were operated upon by conservative surgery for right breast malignancy in the upper halves, one case had modified mastectomy on the left side, one case with right breast malignancy in the lower outer quadrant and one case with fibroadenomas, the results are shown in (Figs. 9-11).

\section{Fig. 10. Septum in breast cancer}

A case of right breast malignancy involving the lower outer quadrant (yellow arrow) for which the patient was subjected to core biopsy (biopsy track= green arrow) for histopathology. Right breast shows an inferior septal vessel of caliber $5.4 \mathrm{~mm}$ (red arrow) with no definite intra-septal. T2W, T2 weighted.

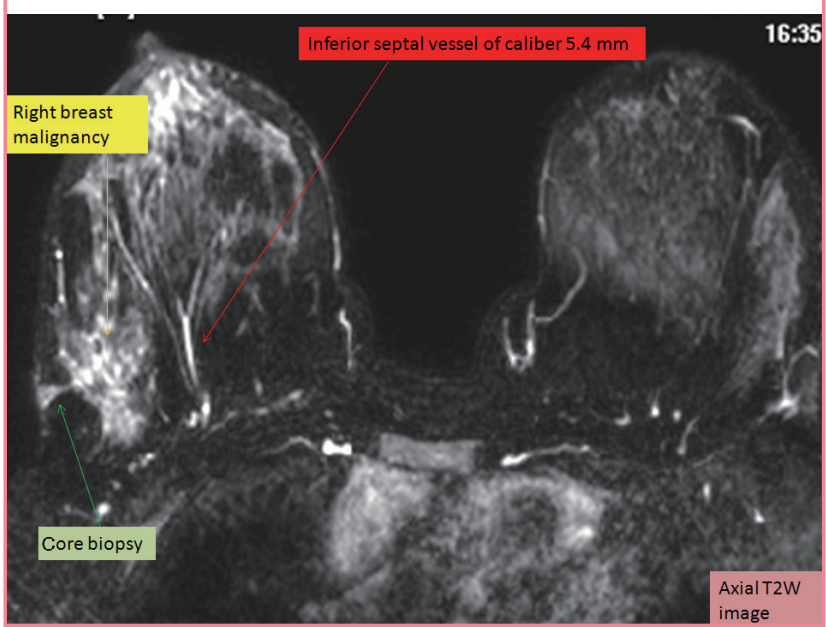

Fig. 11. Septum in fibroglandular predominance

A 19-year-old female with huge breasts; fibroglandular predominance with multiple well defined soft tissue mass lesions (fibroadenomata). On the right side the inferior septum (red arrows) is remarkably thickened with a posterior width of $23 \mathrm{~mm}$ accommodating fat, thinning out anteriorly reaching a thickness of $8 \mathrm{~mm}$, deviated medially by one of the fibroadenomata. In left breast, septum is extremely difficult to verify attributed to the accentuated fibroglandular tissue and multiple deep lesions resting on the pectoral fascia. T2W, T2 weighted.

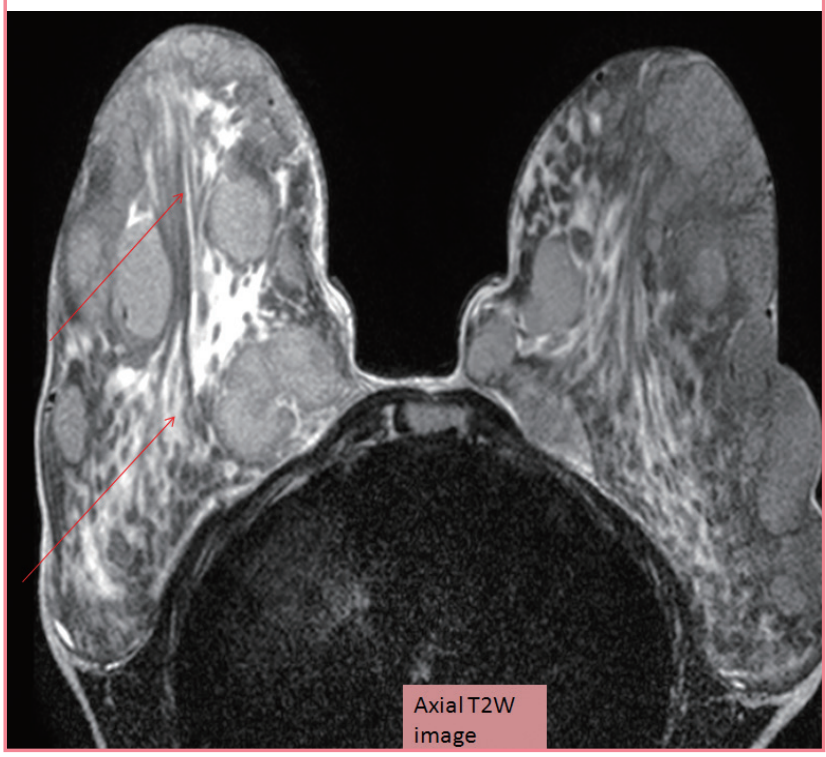

\section{DISCUSSION}

"Cooper" [1] in 1840, described fascial extensions between skin and pectoral fascia, dividing the parenchyma into lobes and lob- 
ules. Since then, all authors referred to his work when writing about ligaments or septa of the breast without further anatomical studies. It was only at the end of the 20th century when anatomical studies began to appear regarding the infra-mammary ligament, supporting or denying its presence [2-5].

According to Taylor and Palmer [13], 1987; the connective tissue in a parenchymatous organ, is what is left over after the glandular tissue has been formed (breast included). This is also the normal route and path for entry of nutrition and sensation for the organ by guiding arteries and nerves in and lymphatics and veins out.

Connective tissue in the breast produces some sort of "curtains" separating the mammary gland into lobes and lobules guiding the major supply within the glandular tissue before spread within and around the secretory units. So it is not surprising to find a vessel or a nerve running within or guided by these connective tissue condensations, the surprising is rather not to find one.

To date, the ligamentous system of the breast comprises deep and superficial components. The deep one includes horizontal, medial vertical, lateral vertical, cranial and posterior ligaments connecting the breast to the chest wall, while the superficial component includes horizontal, vertical medial and vertical lateral ligaments attached to the dermis and defining the breast [14].

In the present study, a median vertical septum is described extending from the mid IMF inferiorly to the lower border of the NAC superiorly and from pectoralis muscle posteriorly to overlying skin anteriorly, dividing the caudal part of breast into medial and lateral compartments. It is formed of two leaflets with a potential space in-between. It is of variable length and thickness and to our knowledge this vertical, centrally located septum was not described before.

Several anatomical studies have given special interest to the ligamentous anatomy in the inferior breast pole and the inframammary region. Riggio et al. [15], 2,000 studied the inframammary region in 6 cadavers and 21 patients during breast surgery. They found neither ligament nor fibrous band taking origin from the superficial fascia at IMF. The only recognized a prepectoralis adherence, its orientation follows the breast shape instead of the inferior pectoral border, providing major resistance to blunt dissection of the superficial fascia from the deep fascia in the central part of the presumed IMF at $5 \mathrm{~cm}$ from the areola at the sixth rib.

Matousek et al. [16], stated that in the inferior pole of the breast, ligaments run obliquely and inferiorly to insert directly into the dermis. They fan out at the level of the fifth rib in a triangular fashion from the periosteum of the superior aspect of

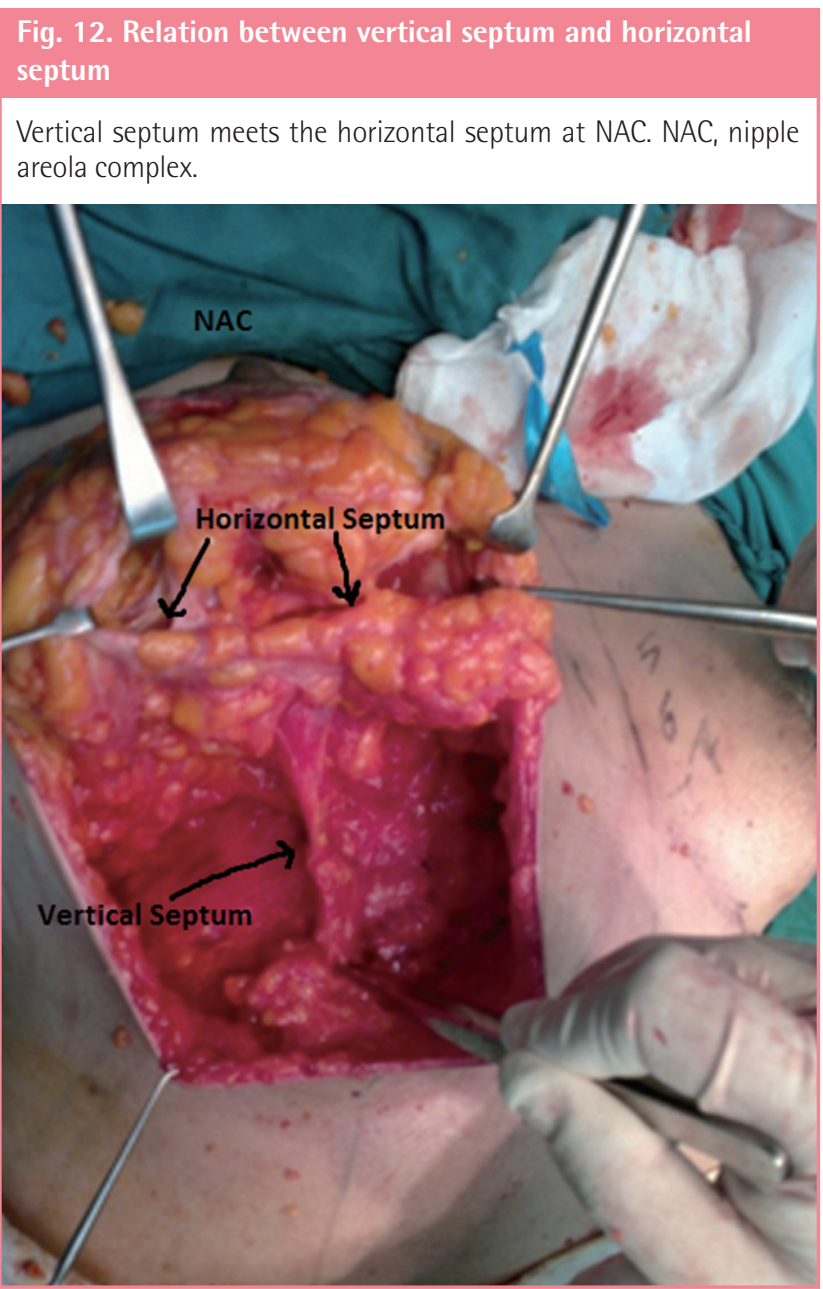

fifth rib inserting into the dermis of the IMF. The remaining superior fibers insert into the inferior pole of the breast. In addition, the condensation has radial fibers running perpendicular to these along the length of the fold.

In 1998, Wuringer et al. [8], described an intra-glandular horizontal septum that originates from the pectoral fascia at the level of fifth rib. At the medial and lateral ends, it is curved upwards to the sternum from the second to the fifth rib stretching into the skin overlying the sternum and along the lateral border of the pectoralis minor respectively to form the medial and lateral vertical ligaments. Also she stated that the origin of the transverse septum from the thoracic wall at the level of fifth rib connected with a ligament originating from the pectoral fascia at the same level, which extends to the IMF which corresponds to Bayati's description which is known to be crescent-shape sagittally oriented. On the contrary our newly described septum was constantly seen running vertically along the breast meridian in the inferior pole of the breast from mid IMF upwards till it meets the horizontal septum at the level of NAC (Figs. 12, 13).With this anatomical variation, in addition to the histological differ- 
Fig. 13. Schematic illustration of the vertical and transverse septa

The horizontal septum is represented in blue and the vertical septum is represented in green in both sagittal (A) and anterior (B) views.

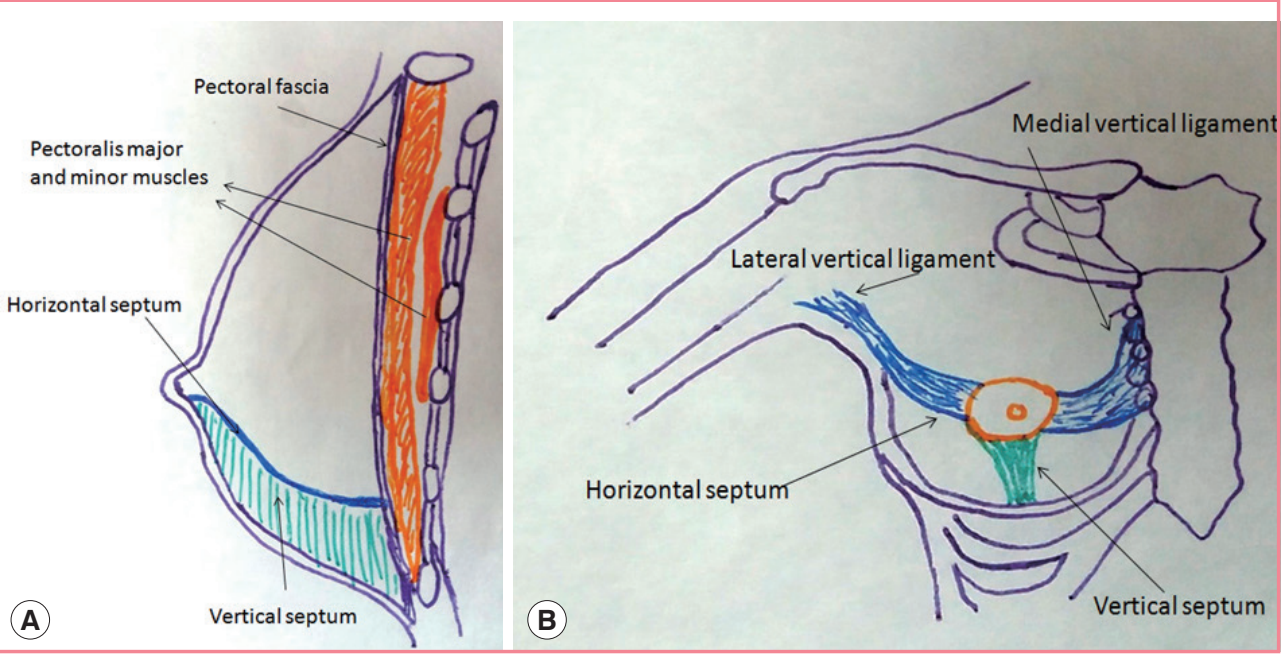

ence proved, both the transverse and vertical septa cannot be mistaken as one entity.

Being a part of breast fascial system, it can change in relation to age, breast size, weight, adiposity and glandular activity [4]. In large fatty breasts, the septal walls are thinned out, attenuated and largely penetrated by fat globules clinically (Fig. 5) and seen as interrupted linear structure on MR imaging (Fig. 8). This correlates with Hammond [17] who stated that although Wuringer septum is uniformly present in breasts with any degree of hypertrophy; it tends to be more distinct in thinner patients, while in breasts with a greater fat content the septum becomes less readily identifiable.

It is logic to assume that the vessel running within this septum, is supplying the NAC in the inferior pedicle type of breast reduction. However, this vessel was not constantly found in either the clinical series or in MRI study. Clinically, this may be related to the limited dissection in this area for fear of affecting the viability of the NAC. The sensitivity of MRI to visualize vessels with a caliber equal to/or less than $2 \mathrm{~mm}$ may not exceed $38 \%$. This fact may explain the lack of appearance of intra-septal vessels in some MR images [18].

Wuringer [19] tightens the vertical extensions of the horizontal ligament, minimizing the descent of NAC in breast reduction operation. In our cases, the two lamina of the vertical septum, based on the NAC (Fig. 3), can be rotated separately to support either a superiorly, medially or a laterally-based pedicle in reduction mammaplasty operations to prevent postoperative bottoming out. This may not be applied in very fatty breasts as the septum may be thinned out discarding its use in large breast. Thus, only small or average sized breasts amenable for augmentation, are the suitable candidates for its use in supporting breast implants in augmentation procedures.
As proved by MRI, the case having breast malignancy in the lower lateral quadrant of the right breast showed thickening of the right septum in comparison to the left. Also in the case with benign growth, the septum is pushed towards the opposite side of the growth and not penetrated. Being a tough fibrous tissue separating infero-medial from infero-lateral compartments, it certainly has a role in delaying the spread of malignancy from one quadrant to another. This oncological importance is yet to be investigated thoroughly by further studies.

The research results describe a new inferior vertical septum which separates the lower half of the breast into two definite anatomical compartments: medial and lateral. This is a true and constant ligament to be added to the ligamentous apparatus of the breast. It is not an anatomical variation or a part of other previously described ligaments and the research will continue in order to postulate possible clinical applications of this vertical septum.

\section{REFERENCES}

1. Cooper AP. Of the internal parts of the breast or mammary gland. In: Cooper A, editor. On the anatomy of the breast. London: Longman, Orme, Green, Brown, and Longmans; 1840. p.48-58.

2. Bayati S, Seckel BR. Inframammary crease ligament. Plast Reconstr Surg 1995;95:501-8.

3. van Straalen WR, Hage JJ, Bloemena E. The inframammary ligament: myth or reality? Ann Plast Surg 1995;35:237-41.

4. Nava M, Quattrone P, Riggio E. Focus on the breast fascial system: a new approach for inframammary fold reconstruction. Plast Reconstr Surg 1998;102:1034-45.

5. Garnier D, Angonin R, Foulon P, et al. The inframammary 
fold: myth or reality? Ann Chir Plast Esthet 1991;36:313-9.

6. Muntan CD, Sundine MJ, Rink RD, et al. Inframammary fold: a histologic reappraisal. Plast Reconstr Surg 2000;105: 549-56.

7. Boutros S, Kattash M, Wienfeld A, et al. The intradermal anatomy of the inframammary fold. Plast Reconstr Surg 1998;102:1030-3.

8. Wuringer E, Mader N, Posch E, et al. Nerve and vessel supplying ligamentous suspension of the mammary gland. Plast Reconstr Surg 1998;101:1486-93.

9. Wuringer E. Secondary reduction mammaplasty. Plast Reconstr Surg 2002;109:812-4.

10. Hall-Findlay EJ. A simplified vertical reduction mammaplasty: shortening the learning curve. Plast Reconstr Surg 1999; 104:748-59.

11. Pike MC, Pearce CL. Mammographic density, MRI background parenchymal enhancement and breast cancer risk. Ann Oncol 2013;24 Suppl 8:viii37-41.

12. Schnall MD, Blume J, Bluemke DA, et al. Diagnostic architectural and dynamic features at breast MR imaging: multicenter study. Radiology 2006;238:42-53.

13. Taylor GI, Palmer JH. The vascular territories (angiosomes) of the body: experimental study and clinical applications. $\mathrm{Br}$ J Plast Surg 1987;40:113-41.

14. Santos DC, Cardoso A, Martins JM, et al. suspensory ligament of the mammary gland: a case report. Aesthetic Plast Surg 2016;40:98-101.

15. Riggio E, Quattrone P, Nava M. Anatomical study of the breast superficial fascial system: the inframammary fold unit. Eur J Plast Surg 2000;23:310-5.

16. Matousek SA, Corlett RJ, Ashton MW. Understanding the fascial supporting network of the breast: key ligamentous structures in breast augmentation and a proposed system of nomenclature. Plast Reconstr Surg 2014;133:273-81.

17. Hammond DC. Atlas of aesthetic breast surgery. New York: Saunders/Elsevier; 2009.

18. Yucel EK, Anderson CM, Edelman RR, et al. AHA scientific statement. Magnetic resonance angiography: update on applications for extracranial arteries. Circulation 1999;100: 2284-301.

19. Wuringer E. Refinement of the central pedicle breast reduction by application of the ligamentous suspension. Plast Reconstr Surg 1999;103:1400-10. 